\title{
Confidence in dental care and public health competency during rural practice among new dental graduates in Thailand
}

This article was published in the following Dove Press journal:

Advances in Medical Education and Practice

16 December 2014

Number of times this article has been viewed

\section{Thunthita Wisaijohn' \\ Rapeepong \\ Suphanchaimat ${ }^{1,2}$ \\ Thitikorn Topothai' \\ Parinda Seneerattanaprayul' \\ Nareerut Pudpong' \\ Weerasak Putthasri'}

'International Health Policy Program, Ministry of Public Health, Nonthaburi, Thailand; ${ }^{2}$ Banphai Hospital, KhonKaen, Thailand
Correspondence: Thunthita Wisaijohn International Health Policy Program, Ministry of Public Health, Tiwanond road, Nonthaburi, II000, Thailand

Tel +6625902381

Fax +6625902385

Email thunthita@ihpp.thaigov.net
Objective: The dental profession has played an important role in the development of the health system in Thailand. However, it is not known if dental graduates' standards of knowledge, skills, and capabilities are fulfilling the health needs of Thais. This study aimed to assess the level of confidence in dental public health competency among final-year dental students who graduated in 2013.

Methods: A cross-sectional survey was conducted among 571 new dental graduates who participated in an official meeting arranged by the Ministry of Public Health in 2013. Self-administered questionnaires were used for collecting data on their confidence levels in selected public-health competencies. Of the total graduates, $72.5 \%$ anonymously responded to the questionnaire. Descriptive and inferential statistics, factor analysis, and stepwise regression were applied for data analysis.

Results: The majority of respondents expressed confidence in their ability to care for patients, but less confidence in public-health and administration competencies. The results also show that there was no significant association between demographic and educational profiles of respondents and confidence in their clinical competency. However, significantly more students who graduated from schools located outside Bangkok and vicinity rated themselves as competent in public health (coefficient $=0.333, P=0.021$ ).

Conclusion: New dentists who graduated from dental schools in Bangkok and vicinity had lower levels of confidence in their public-health competencies compared to those who graduated from dental schools outside Bangkok. Thus, working in rural areas after graduation could help new dentists gain more experience in rural practice, leading to higher confidence levels. The findings from this study could contribute to the improvement of the dental curriculum and contract-bonding policy to work in rural areas.

Keywords: competency, public health, dental school, rural area, factor analysis, stepwise regression

\section{Introduction}

Dentists are important clinical staff of the health workforce, as documented by the World Health Organization in $2010 .{ }^{1}$ It is widely accepted that the health workforce plays a vital role in the health system. Shortage of health staff is a major public health problem in many countries, particularly in developing nations, and Thailand is one of these cases. The country has established policies for decades to increase the health workforce aimed at responding to demands for healthcare in light of the growing population. ${ }^{2}$ Among various cadres of the health workforce in the country, the dental profession is of great importance. ${ }^{3}$ Consequently, a shortage of dentists, inequitable distribution of dental staff, ${ }^{4-6}$ and a lack of competencies 
in dental graduates are major hindrances to enhancing the health status of the population. ${ }^{7}$ Thus, the Ministry of Public Health (MoPH) of Thailand has put much effort into trying to tackle these problems through several health workforce policies. ${ }^{4-6}$

According to the recommendations to improve the health workforce in rural areas proposed by the World Health Organization in 2010, five of the 16 interventions focus on education strategies, such as recruiting students with a rural background, locating health professional schools outside major cities, and clinical rotations in rural areas during studies. ${ }^{1}$ Therefore, since 1960, several new dental schools in Thailand were established outside the capital city with the aim to recruit students from the countryside. ${ }^{8}$ Another vital policy is compulsory rural service through contract bonding with the MoPH, set up since 1967, which is imposed on all dental students in all dental schools in the public sector. Under this contract bond, most dental students have to clinically practice in public hospitals outside Bangkok for at least 3 years after graduation, or pay a fee of USD $\$ 1,330$ to break the contract. ${ }^{2,9,10}$ Financial incentives are one of the mechanisms used to boost the number of dentists in remote areas. ${ }^{2}$ In 1975, an incentive of a USD $\$ 60-\$ 88$ monthly salary was introduced as a supplement for those working at hospitals in remote areas. This salary supplement was gradually increased over the years and, at present, it is USD $\$ 250-\$ 500$ per month. ${ }^{2,11}$

In Thailand, there are two distinct modes of admission for dental students. The first track is called the normal track, whereby any grade 12 student can apply to take the national entrance examination for dental school. Prior to the national entrance exam, some faculty conduct their own recruitment (so-called "direct admission"). The second method of recruitment is the special track, composed of two ongoing national programs. One is the "Collaborative Project to Increase Production of Rural Doctors (CPIRD) program," launched in 1995, and the other is the "One District One Doctor (ODOD)," program launched in 2005., 5, 13 The programs initially focused on doctors, and then were expanded to include dentists.

Consequently, the overall number of dentists in Thailand during the past 2 decades has increased significantly. This is evident from the number of new dental graduates, which rose from 9,038 in 2005 to 12,459 in $2012 .{ }^{14}$ This finding is consistent with the expanding number of dental schools, from only five in 1980 (two in Bangkok, and one each in the northern, northeastern, and southern regions) to ten schools throughout the country as of 2013. Of these ten dental schools, two are operated by private institutions while the other eight are publicly run. ${ }^{15}$ However, despite the dramatic increase in production of dentists, dental public-health competency among dentists required additional improvement. In 1994, the Thai Dental Council was founded to serve as the prime governing body in ensuring professional competency in dental practice. In collaboration with the MoPH and the Consortium of Dental Schools, the Council oversees scientifically based dental education and sets guidelines encompassing a variety of required skills, eg, professionalism, basic knowledge, surgical skills, and oral health promotion. ${ }^{14}$ The standard curriculum is a 6-year study program that consists of basic science in the first year, followed by instructional and laboratory courses in the second and third years, and a clinical internship under the supervision of faculty in the final 3 years. After completing the course, all graduates receive the Doctor of Dental Surgery (DDS) degree from their respective public dental schools and must sit for the National Licensing Examination, held by the Thai Dental Council, in order to be licensed to practice in the country. This means they have to pass the minimum requirement of dental public-health competency as stated in the professional dental curriculum.

Competency is defined as the capability to apply a set of related knowledge, skills, and abilities to successfully perform functions or tasks in a defined work setting, and often serves as the basis for standard that specifies potential measure criteria for assessing skill and knowledge attainment. ${ }^{16}$ Competency is of equal importance to the production of dentists as it is to the production of other health workforce cadres. ${ }^{12,17,18}$ So far, several pieces of literature have explored the level of competencies in other health professions, eg, doctors ${ }^{17}$ and nurses. ${ }^{19}$ However, comparatively little is known regarding whether recent dental graduates have the knowledge, skills, and abilities to meet the health needs of the population. Cowpe et $\mathrm{al}^{20}$ conducted a research study on the profile and competence of graduating dentists to identify the "patient first" attitude as a key competency, which is required for dental graduates. However, more information is still required regarding the factors associated with the level of competency of dental graduates. The review of literature related to dental education research found that several dental programs have used the competencies to guide curriculum content and to provide evidence of curriculum outcomes. ${ }^{21}$

This study aimed to assess the level of confidence in dental competency of newly graduated dentists who acquired their degree in 2013. It is hoped that the results will provide a clearer insight into the relationship between dental competency and the graduates' attributes. In light of the large number of policy interventions introduced since the $1970 \mathrm{~s},{ }^{6,10,22}$ 
including the goal of more-equitable distribution of dentists in remote areas, this knowledge is of great importance for assessing if the current policy interventions are producing an adequate number of dentists with capable skills and for informing future policy directions. This system might, in time, be applied to dental curricula in other countries as well as to improve confidence in dental public-health competency.

\section{Methods}

\section{Study design, population, and sample size}

A cross-sectional survey was conducted among 571 new dental graduates who attended a meeting arranged by the MoPH in April 2013 to choose their workplaces under their mandatory rural services program. The questionnaire was distributed to those new graduates along with their registration documents. Confidentiality of information was strictly kept and verbal consent was granted before filling out the questionnaire. A total of 414 (72.5\%) of the graduates anonymously responded to the questionnaire of this study.

\section{Questionnaire design}

The questionnaire was developed from a brainstorming meeting among researchers with consultation with senior officers in the MoPH to check for content validity. There are three parts in the questionnaire. The first part asks about demographics of the graduates, including age, sex, location of residence for the period from age 1-15 years (urban versus rural), and location of current residence (urban versus rural). The second part looks at the graduates' educational profile, including the location of their dental school (within Bangkok and vicinity versus regional) and mode of admission (normal admission track through competitive national entrance examination ["national exam"] versus special track including direct admission to each dental school and regional quota on demand ["non-national entrance exam"]). The third part is a competency self-assessment. In the competency part, respondents are asked to assess the level of their confidence using a Likert scale, ranging from 1 (least confident) to 5 (most confident) for 12 identified competencies, which are: 1) public health, 2) health administration, 3) communication, 4) interprofessional collaboration, 5) general dental care, 6) dental care for patients with systemic diseases, 7) restorative care, 8) oral surgery, 9) pediatric clinic, 10) prosthodontic clinic, 11) periodontal clinic, and 12) oral diagnosis.

Completed questionnaires were dropped into a collection box anonymously. All three parts were arranged in a single attachment. It should be noted that "urban" in this study refers to Bangkok and vicinity (two surrounding provinces: Nonthaburi and Samut Prakarn), Hat Yai City in Songkhla Province, and provincial cities in other provinces. All other locations were deemed "rural."

\section{Data analysis}

STATA XI software (StataCorp LP, College Station, TX, USA) was used for data analysis. The analysis consisted of four parts. 1) Descriptive and inferential statistics were used to understand the sociodemographic and educational profiles of the graduates. Pearson's correlation, chi-square test, and Student's $t$-test were used to determine the association between the location of each dental school and the personal attributes of the students. 2) Level of confidence in each competency was compared between two modes of admission by assessing its mean score. 3) A composite score was constructed using exploratory factor analysis of the twelve competency questions. Principal component analysis with Varimax rotation was applied to identify factors which addressed over $80 \%$ of variance..$^{23}$ The composite score of each factor was calculated using Bartlett's method. 4) Stepwise regression was applied to assess the competency composite score against the demographic and educational profiles of respondents. Significance level of removal or addition into the model was set at 0.2 . Location of dental schools and any attribute that showed significant association with location of dental school in the Part 1 analysis would always be included in the model.

\section{Results \\ General characteristics of the newly graduated dentists}

In 2013, there were 571 newly graduated dentists in Thailand. Of these, 414 graduates voluntarily participated in this study, which constitutes a $72.5 \%$ response rate. A majority of the new dental graduates were female (69.7\%) and had a rural background (74.6\%). Selected characteristics of the newly graduated dentists in this study are presented in Table 1. The result of chi-square test cross-tabulating graduates' profiles and the location of dental schools suggests that non-national entrance exams were significantly related to having a study background in dental schools in the upcountry setting $(P=0.002)$.

\section{Confidence in the dental competency of new graduates}

Table 2 summarizes the confidence levels for the 12 competencies listed in this study. Overall, graduates from regional 
Table I Characteristics of the new dental graduates in Thailand in 2013

\begin{tabular}{|c|c|c|c|c|}
\hline Sample profile* & $\begin{array}{l}\text { Graduated from Bangkok } \\
\text { and vicinity dental schools } \\
\text { Number }(\%)(n=2 I I)\end{array}$ & $\begin{array}{l}\text { Graduated from regional } \\
\text { dental schools } \\
\text { Number }(\%)(n=\mid 73)\end{array}$ & Test & $P$-value \\
\hline Mean age, years (SD) & $24.3(1.5)$ & $24.3(0.7)$ & Student's $t$ test & 0.812 \\
\hline \multicolumn{5}{|l|}{ Sex } \\
\hline - Female & $170(70.5)$ & $119(68.8)$ & Chi-square & 0.702 \\
\hline - Male & 7I (29.5) & $54(31.2)$ & & \\
\hline \multicolumn{5}{|c|}{ Location of residence during age $I-15$ years old } \\
\hline - Urban & $188(78.3)$ & $121(70.8)$ & Chi-square & 0.080 \\
\hline - Rural & $52(21.7)$ & $50(29.2)$ & & \\
\hline \multicolumn{5}{|l|}{ Location of current residence } \\
\hline - Urban & $189(79.8)$ & $123(72.4)$ & Chi-square & 0.082 \\
\hline - Rural & $48(20.2)$ & $47(27.6)$ & & \\
\hline \multicolumn{5}{|l|}{ Admission mode } \\
\hline - Non-national entrance exam & $125(5 \mid .9)$ & $115(66.9)$ & Chi-square & $0.002^{\dagger}$ \\
\hline - National exam & II $6(48.1)$ & $57(33.1)$ & & \\
\hline
\end{tabular}

Notes: *Number of data, where information about location of dental schools could not identified (missing data) was 5 (I.2\% of respondents). ${ }^{\dagger}$ Statistically significant at $P<0.05$. Abbreviations: $n$, number; SD, standard deviation.

dental schools were more professionally confident than those from schools in Bangkok and vicinity. Dental general care, restorative and periodontal competencies received the highest confidence levels, while public-health and health-administration competencies received the lowest confidence levels.

\section{Factors affecting competency of newly graduated dentists}

The results of the analysis determining the important factors that influenced self-assessment competencies of all dentists are presented in Tables 3-5.

Table 3 displays the results from the principal component analysis after Varimax rotation, while Table 4 shows a factor loading matrix of all 12 competencies. Of the five factors produced by explanatory factor analysis, factor 1 and factor 2 produced an eigenvalue of more than 1, and these two factors accounted for $87.5 \%$ of the total variance. These factors were not named at this juncture. After exploring the factor-loading matrix, factor 1 appeared to be associated with various clinical skills without any distinctive pattern (ie, the load by public-health competency was 0.144 , and the load by dental system care was 0.307 ), while factor 2 was more focused on public health (load $=0.707)$ and administrative competency (load $=0.704)$.

As a consequence, factor 1 and factor 2 were renamed "clinical competency" and "public health competency."

A composite score was then calculated for both factors by Bartlett's formula, and this score was used as the dependent variable for stepwise regression in the next step of analysis.

Table 2 Mean and mode of each competency level, by school type

\begin{tabular}{|c|c|c|c|c|c|c|}
\hline \multirow[t]{2}{*}{ Variable } & \multicolumn{2}{|c|}{ All graduates } & \multicolumn{2}{|c|}{ Bangkok and vicinity dental schools } & \multicolumn{2}{|c|}{ Regional dental schools } \\
\hline & Mean (SD) & $\begin{array}{l}\text { Mode (\% of } \\
\text { respondents) }\end{array}$ & Mean (SD) & $\begin{array}{l}\text { Mode (\% of } \\
\text { respondents) }\end{array}$ & Mean (SD) & $\begin{array}{l}\text { Mode }(\% \text { of } \\
\text { respondents) }\end{array}$ \\
\hline Health administration & $3.01(0.68)$ & $3(63.83)$ & $2.95(0.69)$ & $3(60.17)$ & $3.08(0.66)$ & $3(69.01)$ \\
\hline Public health & $3.17(0.67)$ & $3(61.26)$ & $3.11(0.70)$ & $3(61.00)$ & $3.26(0.63)$ & $3(61.63)$ \\
\hline Dental system care & $3.28(0.61)$ & $3(58.74)$ & $3.30(0.60)$ & $3(60.42)$ & $3.26(0.63)$ & $3(56.40)$ \\
\hline Pediatric clinic & $3.33(0.73)$ & $3(5 \mid .33)$ & $3.112(0.70)$ & $3(54.77)$ & $3.256(0.63)$ & $3(49.5 \mathrm{I})$ \\
\hline Oral diagnosis & $3.40(0.62)$ & $3(52.30)$ & $3.48(0.56)$ & $3(54.36)$ & $3.50(0.65)$ & $3(49.42)$ \\
\hline Oral surgery & $3.47(0.68)$ & $3(49.39)$ & $3.44(0.66)$ & $3(51.04)$ & $3.52(0.70)$ & $3(47.09)$ \\
\hline Prosthodontic clinic & $3.49(0.70)$ & $3(44.31)$ & $2.95(0.69)$ & $4(46.89)$ & $3.08(0.66)$ & $3(45.93)$ \\
\hline Interprofessional skill & $3.49(0.60)$ & $4(48.43)$ & $3.48(0.56)$ & $3(48.96)$ & $3.50(0.65)$ & $4(49.42)$ \\
\hline Communication & $3.67(0.72)$ & $4(50.85)$ & $3.64(0.69)$ & $4(51.04)$ & $3.71(0.76)$ & $4(50.58)$ \\
\hline Periodontal clinic & $3.77(0.64)$ & $4(57.87)$ & $3.64(0.69)$ & $4(60.58)$ & $3.71(0.76)$ & $4(54.07)$ \\
\hline Dental general care & $3.81(0.60)$ & $4(6 \mid .65)$ & $3.76(0.57)$ & $4(64.73)$ & $3.88(0.64)$ & $4(57.31)$ \\
\hline Restorative clinic & $3.83(0.65)$ & $4(58.84)$ & $3.82(0.62)$ & $4(60.58)$ & $3.84(0.68)$ & $4(56.40)$ \\
\hline
\end{tabular}

Abbreviation: SD, standard deviation. 
Table 3 Level of potential factors influencing dentists' competency (principal component analysis)

\begin{tabular}{lllll}
\hline Factor & Eigenvalue & Difference & Proportion & Cumulative \\
\hline Factor I & 2.702 & 1.091 & 0.548 & 0.548 \\
Factor 2 & 1.610 & 0.891 & 0.327 & 0.875 \\
Factor 3 & 0.719 & 0.073 & 0.146 & 1.021 \\
Factor 4 & 0.646 & 0.522 & 0.131 & 1.152 \\
Factor 5 & 0.124 & 0.116 & 0.025 & 1.178 \\
Factor 6 & 0.008 & & 0.002 & 1.179 \\
\hline
\end{tabular}

The stepwise regression presents the extent to which each individual attribute was associated with the outcome variables, namely, "clinical competency" and "public health competency," which were the products from factor analysis in the previous section. A positive coefficient value refers to positive correlation with the outcome of interest, since it would increase the factor score, while a negative coefficient value reflects a decrease in factor score. Results suggest that demographic and educational profiles of respondents were not significantly associated with their self-confidence in clinical competency. According to the cutoff point of $P=0.2$ as the criterion for variable selection, none of the variables except "location of dental school" and "mode of admission" (which were fixed variables) were recruited into the model. Students from the dental schools outside Bangkok and its vicinity were more likely to have a higher level of public health competency, as shown by a positive coefficient $(0.333)$ with statistical significance $(P=0.021)$. The level of clinical competency was higher in students from outside Bangkok and vicinity (coefficient $=0.223$ ) and those who were admitted through the national entrance exam (coefficient $=0.116$ ). However, there was no significant association between these attributes and level of clinical competency. Note that students in the non-national entrance exam group appeared to have higher confidence levels in public health competency than national-entrance-exam students (coefficient $=-0.057$ ), although no statistical significance was observed $(P=0.689)$. See Table 5.

\section{Discussion}

This study found that, even in the rural dental system, dentists who graduated from regional dental schools had higher confidence level than those who graduated from schools in Bangkok and its vicinity. The dentists participating in this study expressed confidence in caring for patients, but less confidence in public-health and administration competencies. In general, dental care, restorative, and periodontal competencies were of the highest confidence level. However, detailed exploratory analysis and stepwise regression found that demographic and educational profiles of respondents had no significant association with their confidence in clinical competency. It was also found that the location of dental schools outside Bangkok and vicinity tend to be significantly associated with an increase in publichealth competency (coefficient $=0.333, P=0.021$ ).

This finding corresponds with the study of Suphanchaimat et $\mathrm{al},{ }^{17}$ which found that the doctors graduating from the CPIRD program were more confident in their general medical knowledge than those who graduated from the normal program. This may be because the students on CPIRD tracks have a 3-year training program implemented by professional clinical staff of medical education centers from regional and provincial hospitals of the $\mathrm{MoPH}$, which are normally located outside of Bangkok and vicinity. ${ }^{24}$ These students tend to have greater opportunity to care for patients more closely and practice procedures through hands-on experience under the supervision of senior physicians and lecturers. This could give them higher confidence than medical students who graduated from the regular system, who

Table 4 Levels of influential factors by various types of dental schools

\begin{tabular}{|c|c|c|c|c|c|c|c|}
\hline Variable & Factor I & Factor 2 & Factor 3 & Factor 4 & Factor 5 & Factor 6 & Uniqueness \\
\hline Public health & 0.144 & 0.707 & 0.139 & 0.129 & 0.017 & 0.014 & 0.443 \\
\hline Health administration & 0.101 & 0.704 & 0.093 & 0.137 & 0.007 & -0.008 & 0.467 \\
\hline Communication & 0.375 & 0.336 & 0.046 & 0.472 & 0.087 & -0.005 & 0.514 \\
\hline Interprofessional skill & 0.315 & 0.335 & 0.019 & 0.492 & -0.052 & 0.008 & 0.543 \\
\hline Dental general care & 0.582 & 0.155 & 0.258 & 0.284 & $-0.17 \mid$ & -0.011 & $0.46 I$ \\
\hline Dental system care & 0.307 & 0.229 & 0.502 & 0.032 & -0.054 & -0.012 & 0.597 \\
\hline Restorative clinic & 0.752 & 0.070 & 0.162 & 0.201 & -0.040 & -0.027 & 0.360 \\
\hline Oral surgery & 0.423 & 0.242 & 0.403 & 0.076 & 0.164 & 0.007 & 0.568 \\
\hline Pediatric clinic & 0.434 & 0.321 & 0.240 & -0.002 & 0.172 & 0.002 & 0.622 \\
\hline Prosthodontic clinic & 0.583 & 0.253 & 0.101 & 0.083 & 0.094 & 0.008 & 0.571 \\
\hline Periodontal clinic & 0.726 & 0.139 & 0.092 & 0.095 & 0.101 & 0.037 & 0.425 \\
\hline Oral diagnosis & 0.447 & 0.254 & 0.325 & 0.038 & 0.066 & 0.070 & 0.619 \\
\hline
\end{tabular}


Table 5 Association between two potential factors and location of dental school and educational profiles of respondents

\begin{tabular}{|c|c|c|c|c|c|}
\hline \multirow{2}{*}{$\begin{array}{l}\text { Factor } \\
\text { Factor I: clinical competency* }\end{array}$} & \multirow[t]{2}{*}{ Coefficient } & \multirow[t]{2}{*}{ Standard error } & \multirow[t]{2}{*}{$P$-value } & \multicolumn{2}{|c|}{$\begin{array}{l}95 \% \text { confidence } \\
\text { interval }\end{array}$} \\
\hline & & & & & \\
\hline Regional dental school (versus Bangkok and vicinity) & 0.223 & 0.138 & 0.107 & -0.049 & 0.496 \\
\hline National entrance (versus non-national entrance) & 0.116 & 0.138 & 0.400 & -0.155 & 0.388 \\
\hline Constant & -0.149 & 0.110 & 0.176 & -0.366 & 0.067 \\
\hline \multicolumn{6}{|l|}{ Factor 2: public health competency** } \\
\hline Regional dental school (versus Bangkok and vicinity) & $0.333^{\dagger}$ & 0.143 & 0.021 & 0.051 & 0.614 \\
\hline National entrance (versus non-national entrance) & -0.057 & 0.143 & 0.689 & -0.338 & 0.223 \\
\hline Constant & -0.123 & 0.114 & 0.282 & -0.347 & 0.101 \\
\hline
\end{tabular}

Notes: $* R^{2}=0.0023, * * R^{2}=0.0101$. 'Statistically significant at $P<0.05$.

generally study and practice in university hospitals located in urban areas. In general, centrally located medical schools are usually larger in size and provide more health care services than regional medical schools. Therefore, training medical students with practical, intimate, and hands-on-teaching in urban medical schools is more limited than in medical schools in the region or rural areas. ${ }^{17}$ This finding was also found in the previous studies done by Wilson et $\mathrm{al}^{25}$ in South Africa and by Eley et $\mathrm{al}^{26,27}$ in Australia. Among those studies, one indicated that the school location could have some effect on the level of confidence in dental health care. ${ }^{28}$

This study confirmed that the dental curriculum should be improved by putting more emphasis on dental public-health competency. The research on the dental curriculum conducted by Komabayashi et $\mathrm{al}^{22}$ found that the Thai dental curriculum was similar to the curricula of the United States, Japan, Korea, and the People's Republic of China. However, the Thai curriculum puts more emphasis on dental health and community dental perspectives, which are necessary to prepare the graduates for working in the public hospitals outside Bangkok for the first three years after graduation. The Thai curriculum focuses on community dental health to promote sustainable, effective practices in rural communities. Besides, the study done by Komabayashi et $\mathrm{al}^{22}$ showed that new dental graduates had lower confidence in caring for patients with rare conditions, which is contradictory to the findings in the present study as the graduates in this study appear to have confidence in this area. Having real practice for medical, dental, and pharmaceutical

all schools Within Bangkok and vicinity $\quad$ Outside Bangkok and vicinity

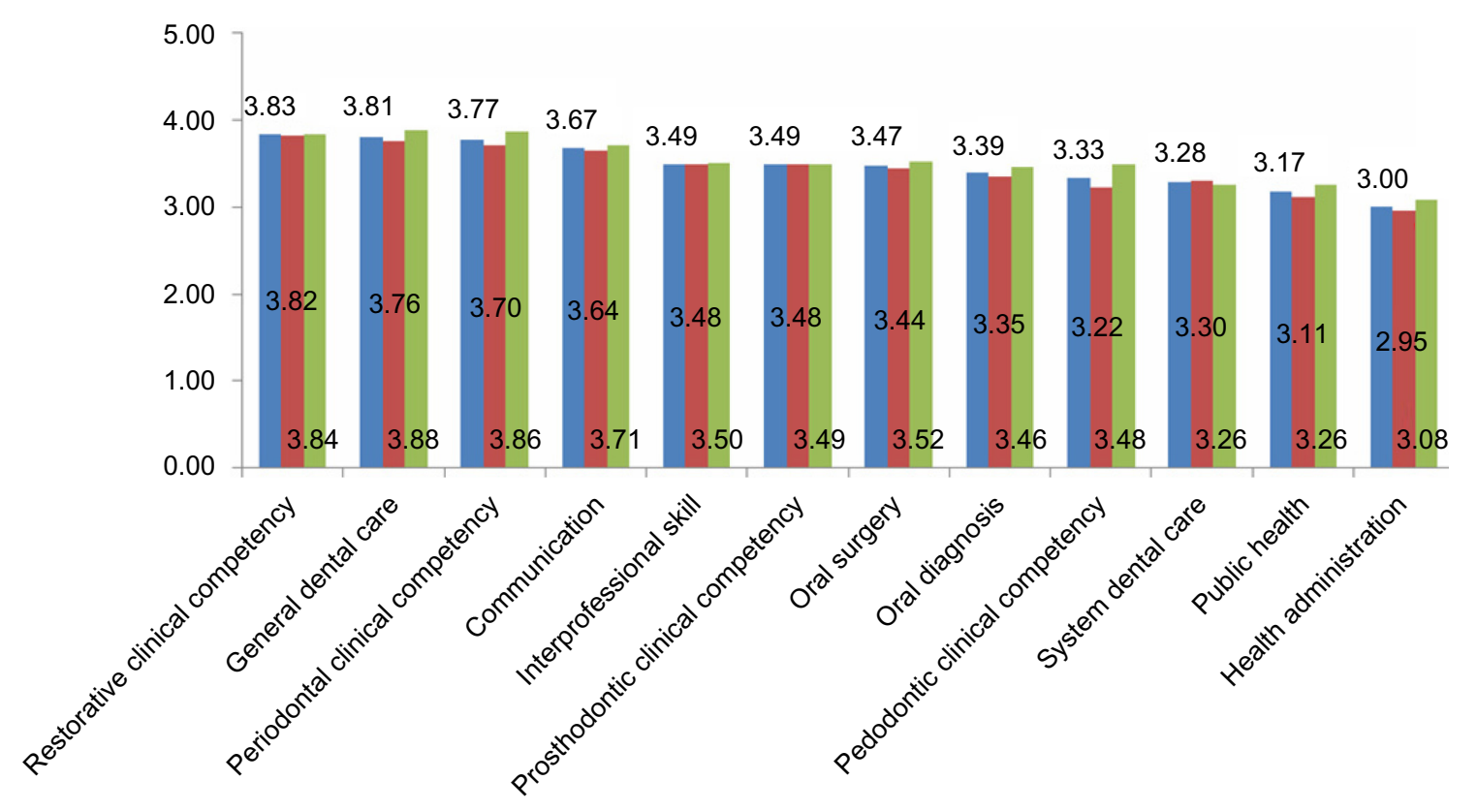

Figure I Mean scores of each competency, by school type. 
graduates is important for preparing graduates to work in rural areas, as confirmed by the study of Wisaijohn et al. ${ }^{29}$ However, Wisaijohn et al found that Bangkok and vicinity students had a low desire to work in rural Thailand. Likewise, a study by Shapiro et $\mathrm{al}^{8}$ found that new medical graduates were generally more interested in clinical specialization than in primary care services. Therefore the medical curriculum should be adapted to suit the current health system, which highlights planning, prevention and health promotion, and increasing community health skills. Shankar and Thapa ${ }^{30}$ recommended that the educational system should be changed to increase motivation for students to provide health care in rural areas by reducing the training on how to use advanced technology.

Overall the findings from this study suggest that the dental teaching system needs improvement, and dental public-health care and administration competencies should be strengthened and should be emphasized in the dental curriculum. The findings from this study can also be applied to improve teaching and learning skills for rural dentists. Similarly, dental schools in Bangkok and its vicinity should work more closely with rural hospitals and/or regional dental schools in order to provide more opportunity for dental students to practice in rural areas after graduation. More rural practice could build up the graduates' confidence in general dental procedures and situations unique to those rural areas.

In addition, the background characteristics of dental students and their self-assessment presented in this study could be used for determining the admission policy, curriculum development, and teaching of dental health care for dental academic institutions. Dental course managers may wish to consider teaching more courses or providing learning activities related to administration and public-health problems or improved methods of teaching in the areas in which the students have less confidence (eg, community dental services). Their confidence in those fields should also be enhanced by providing more practice in rural settings after graduation.

\section{Limitations}

This study has several limitations. The first is that a sample that includes only dental graduates who have a contract with the MoPH may not be completely representative of the 641 dental graduates in that year. This is because the dental graduates who did not have a contract with the MoPH did not participate in this study and, of those who did, some did not answer the questionnaire. In future studies, this limitation could be resolved by studying final-year students at the end of their education, since it is easier to track responses to the questionnaires at graduation. Secondly, data from a quantitative survey lack insights that may be obtained by interviews or discussion groups. Thus, future studies should include a combination of questionnaire survey and interview in order to provide more comprehensive and meaningful data. There has been criticism of self-assessment as a means of evaluating competency and that it is not as effective as external assessment. Lastly, since this was not a comprehensive study, one must take into account that there are other factors in addition to the factors identified in this study, such as forms of teaching and learning of each dental school, that may change over time. Adding other factors may result in a more-comprehensive analysis of the multiple regression coefficients, which will in turn provide more accurate results.

\section{Conclusion}

On the basis of the study results, new dental graduates are less confident in their competency in public health than in clinical competence. Working in rural areas to gain more experience in rural practice, particularly for Bangkok graduates, could rectify this problem. The following strategies could be used in the dental education system to provide more experience in rural practice, particularly for those who graduate from schools in Bangkok and vicinity: 1) increase opportunities for dental students likely to choose rural careers, such as growing up in a rural area, under the CPIRD project; 2) assess if the current curriculum adequately emphasizes skills such as evidence-based practice, professionalism, communication, and interpersonal skill; and 3) support rural programs such as training programs in rural public-health and administration dentistry. These factors should be considered to encourage graduates to practice in rural areas, and an appropriate curriculum should be developed to increase their readiness for working in these areas.

\section{Author contributions}

All authors made substantial contributions to data generation and analysis, drafting, or critical revisions of the manuscript, and approval for the final version to be published.

\section{Acknowledgments}

The authors would like to thank Dr Viroj Tangcharoensathien and Dr Suwit Wibulpolprasert, who continuously encouraged everyone involved in this study. We also appreciate International Health Policy Program staff for their efforts in coordination of field work and data collection.

\section{Disclosure}

This study had no funding support and the authors declare no competing interests. The National Ethical Review Committee 
waived ethical clearance as this is a regular monitoring work conducted by the government, confirmed by ethical review committee: IHRP 47.2/2553 dated January 28, 2553 BE (2010 AD). However, informed consent was sought and the protection of confidentiality was strictly followed.

The authors report no other conflicts of interest in this work.

\section{References}

1. World Health Organization. Increasing Access to Health Workers in Remote and Rural Areas through Improved Retention: Global Policy Recommendation. Geneva, Switzerland: World Health Organization; 2010. Available from: http://whqlibdoc.who.int/ publications/2010/9789241564014_eng.pdf. Accessed September 21, 2014.

2. Wibulpolprasert S, Pengpaibon P. Integrated strategies to tackle the inequitable distribution of doctors in Thailand: four decades of experience. Hum Resour Health. 2003;1(1):12.

3. World Health Organization. Thailand: Health Profile. Geneva, Switzerland: World Health Organization; 2014. Available from: http:// www.who.int/gho/countries/tha.pdf. Accessed September 21, 2014.

4. NaRanong A, NaRanong V. The effects of medical tourism: Thailand's experience. Bull World Health Organ. 2011;89(5):336-344.

5. Lexomboon D, Punyashingh K. Supply projection for dentists, Thailand (2000-2030). Human Resource for Health Development Journal. 2000;4(2):1-13.

6. Hosanguan C. Geographic distribution and opinions relating to practice location of Chulalongkorn dental graduates under the policies of compulsary service requirement and universal coverage. Chulalongkorn University Dental Journal. 2013;30(2):85-102.

7. World Health Organization. Working Together for Health: The World Health Report 2006. Geneva, Switzerland: World Health Organization; 2006. Available from: http://www.who.int/whr/2006/ whr06_en.pdf?ua=1. Accessed September 21, 2014.

8. Shapiro MC, Shapiro RA, Ubolcholket S. Medical education in Thailand. Med Educ. 1992;26(3):251-258.

9. Patcharanarumol W, Tangcharoensathein V, Limwattananon S, et al. Why and how did Thailand achieve good health at low cost? In: Balabanova D, McKee M, Mills A, editors. 'Good Health at Low Cost'25 Years On: What Makes a Successful Health System? 1st ed. London, UK: London School of Hygiene and Tropical Medicine; 2011:193-223. Available from: http://ghlc.lshtm.ac.uk/files/2011/10/GHLC-book.pdf. Accessed September 21, 2014.

10. Hosanguan C. Factors related to turnover intention among Thai dentists. Chulalongkorn University Dental Journal. 2013;35(1):27-38.

11. Tangcharoensathien V, Limwattananon S, Suphanchaimat R, Patcharanarumol W, Sawaengdee K, Putthasri W. Health workforce contributions to health system development: a platform for universal health coverage. Bull World Health Organ. 2013;91(11):874-880.

12. Suphanchaimat R, Wisaijohn T, Thammathacharee N, Tangcharoensathien V. Projecting Thailand physician supplies between 2012 and 2030: application of cohort approaches. Hum Resour Health. 2013;11(1):3.

13. Lertsukprasert $\mathrm{S}$. Collaborative project to increase production of rural doctor to tavle physician shortage problem of Ministry of Public Health. J Health Sci. 2008;17:1906-1914.
14. The Dental Council Thailand. Professional competency [webpage on the Internet]. Nontaburi, Thailand; 2014. Available from: http://www. dentalcouncil.or.th/eng/professional.php. Accessed December 22, 2013.

15. Western University. University history [webpage on the Internet]. Bangkok, Thailand: Western University; 2014. Available from: http:// www.western.ac.th/western/Web_Version13/history.php. Accessed August 12, 2013. Thai.

16. CareerOneStop. Develop a competency model [webpage on the Internet]. State of Minnesota; 2014. Available from: http://www. careeronestop.org/competencymodel/userguide_competency.aspx. Accessed December 22, 2013.

17. Suphanchaimat R, Topothai T, Thaichinda C, Pagaiya N, Kasemsub V, Wisaijohn T. Newly medical graduates' confidence in medical and public-health competency and its relationship with the collaborative project to increase production of rural doctors (CPIRD) and other related factors: exploratory factor analysis and multiple regression. $J$ Health Syst Res. 2012;6(4):455-466.

18. Thirawat J. Survey of opinions on competencies standard in dentistry for new dental graduates. Chulalongkorn University Dental Journal. 2013;30(3):287-302.

19. Istomina N, Suominen T, Razbadauskas A, Martinkènas A, Meretoja R, Leino-Kilpi H. Competence of nurses and factors associated with it. Medicina (Kaunas). 2011;47(4):230-237.

20. Cowpe J, Plasschaert A, Harzer W, Vinkka-Puhakka H, Walmsley AD. Profile and competences for the graduating European dentist - update 2009. Eur J Dent Educ. 2010;14(4):193-202.

21. Boyd MA, Gerrow JD, Chambers DW, Henderson BJ. Competencies for dental licensure in Canada. J Dent Educ. 1996;60(10):842-846.

22. Komabayashi T, Srisilapanan P, Korwanich N, Bird WF. Education of dentists in Thailand. Int Dent J. 2007;57(4):274-278.

23. Child D. Chapter 3: The orthogonal extraction of factors. In: Child D. The essentials of factor analysis. 3rd ed. New York, NY: Continuum International Publishing Group. 2006.

24. Putthasri W, Suphanchaimat R, Topothai T, Wisaijohn T, Thammathacharee N, Tangcharoensathien V. Thailand special recruitment track of medical students: a series of annual cross-sectional surveys on the new graduates between 2010-2012. Hum Resour Health. 2013;11:47.

25. Wilson NW, Bouhuijs PA, Conradie HH, Reuter H, Van Heerden BB, Marais B. Perceived educational value and enjoyment of a rural clinical rotation for medical students. Rural Remote Health. 2008;8(3):999.

26. Eley DS. Postgraduates' perceptions of preparedness for work as a doctor and making future career decisions: support for rural, non-traditional medical schools. Educ Health (Abindon). 2010;23(2):374.

27. Eley DS. Junior doctors' perceptions of their preparedness for hospital work: support for the rural clinical school model as a key to better preparation. Med J Aust. 2010;192(2):109-110.

28. Kapol N, Maitreemit P, Pongcharoensuk P, Armstrong EP. Evaluation of curricula content based on Thai pharmacy competency standards. Am J Pharm Educ. 2008;72(1):09.

29. Wisaijohn T, Thammatacharee N, Suphanchaimat R, Pudpong N, Putthasri W. Factors and attitudes related to the decision of doctors, dentists, and pharmacists who graduated in 2012 to practice in rural areas. Journal of Health Science. 2013;22:596-607.

30. Shankar PR, Thapa TP. Student perception about working in rural Nepal after graduation: a study among first- and second-year medical students. Hum Resour Health. 2012;10:27. Available from: http://www.humanresources-health.com/content/pdf/1478-4491-10-27.pdf. Accessed July 24, 2013. 
Advances in Medical Education and Practice

Dovepress

\section{Publish your work in this journal}

Advances in Medical Education and Practice is an international, peerreviewed, open access journal that aims to present and publish research on Medical Education covering medical, dental, nursing and allied health care professional education. The journal covers undergraduate education, postgraduate training and continuing medical education including emerging trends and innovative models linking education, research, and health care services. The manuscript management system is completely online and includes a very quick and fair peer-review system. Visit http://www.dovepress.com/testimonials.php to read real quotes from published authors.

Submit your manuscript here: http://www.dovepress.com/advances-in-medical-education-and-practice-journal 